\title{
Engineering Prototype for a Compact Medical Dielectric Wall Accelerator
}

A. Zografos, A. Hening, V. Joshkin, K. Leung, D. Pearson, H. Pearce-Percy, M. Rougieri, Y. Parker, J. Weir, D. Blackfield, Y. Chen, G. Caporao, S. Falabella, G. Guethlein, S. Hawkins, S. D. Nelson, B. Poole, J. Watson, R. W. Hamm, R. Beckerd, T. Brown

August 26, 2011

2011 International Particle Accelerator Conference San Sebastian, Spain September 4, 2011 through September 9, 2011 
This document was prepared as an account of work sponsored by an agency of the United States government. Neither the United States government nor Lawrence Livermore National Security, LLC, nor any of their employees makes any warranty, expressed or implied, or assumes any legal liability or responsibility for the accuracy, completeness, or usefulness of any information, apparatus, product, or process disclosed, or represents that its use would not infringe privately owned rights. Reference herein to any specific commercial product, process, or service by trade name, trademark, manufacturer, or otherwise does not necessarily constitute or imply its endorsement, recommendation, or favoring by the United States government or Lawrence Livermore National Security, LLC. The views and opinions of authors expressed herein do not necessarily state or reflect those of the United States government or Lawrence Livermore National Security, LLC, and shall not be used for advertising or product endorsement purposes. 


\section{ENGINEERING PROTOTYPE FOR A COMPACT MEDICAL DIELECTRIC WALL ACCELERATOR*}

Anthony Zografos ${ }^{\mathrm{a}}$, Terence Brown ${ }^{\mathrm{a}}$, Andi Hening ${ }^{\mathrm{a}}$, Vladimir Joshkin ${ }^{\mathrm{a}}$, Kevin Leung ${ }^{\mathrm{a}}$, Dave Pearson $^{\mathrm{a}}$, Henry Pearce-Percy ${ }^{\mathrm{a}}$, Mario Rougieri ${ }^{\mathrm{a}}$, Yoko Parker ${ }^{\mathrm{a}}$, John Weir ${ }^{\mathrm{a}}$, Donald Blackfield ${ }^{\mathrm{b}}$, Yu-Jiuan Chen ${ }^{\mathrm{b}}$, George Caporaso ${ }^{\mathrm{b}}$, Steven Falabella ${ }^{\mathrm{b}}$, Gary Guethlein ${ }^{\mathrm{b}}$, Steve Hawkins ${ }^{\mathrm{b}}$, Scott Nelson ${ }^{b}$, Brian Poole ${ }^{\mathrm{b}}$, Jim Watson ${ }^{\mathrm{b}}$, Robert W. Hamm ${ }^{\mathrm{c}}$ and Reinard Beckerd ${ }^{\mathrm{d}}$

${ }^{a} C P A C$, Livermore, $C A,{ }^{b}$ Lawrence Livermore National Laboratory, Livermore, $C A,{ }^{c} R \& M$ Technical Enterprises, Pleasanton, CA, ${ }^{d}$ Scientific Software Solutions, Gelnhausen, Germany

\section{Abstract}

A compact accelerator system architecture based on the dielectric wall accelerator (DWA) for medical proton beam therapy has been developed by the Compact Particle Acceleration Corporation (CPAC). The major subsystems are a Radio Frequency Quadrupole (RFQ) injection system, a pulsed kicker to select the desired proton bunches, and a DWA linear accelerator incorporating a high gradient insulator (HGI) with stacked Blumleins to produce the required acceleration energy. An engineering prototype has been constructed and characterized, and these results will be used within the next three years to develop an extremely compact 150 $\mathrm{MeV}$ system capable of modulating energy, beam current, and spot size on a shot-to-shot basis.

\section{CPAC'S SYSTEM ARCHITECTURE}

Proton beam therapy (PBT) for cancer treatment is considered superior to other conventional external beam therapy such as X-rays because of its ability to precisely locate the radiation dosage and avoid collateral damage to neighbouring healthy tissue. Tumours of different sizes and depths can be effectively treated using the proton beam's highly localized Bragg peak by tuning the energy profile. The current dedicated PBT systems, as well as the limited converted physics facilities were all constructed with large footprint accelerators that are expensive to build and maintain. The Compact Particle Acceleration Corporation (CPAC) is leveraging advances in high gradient insulators (HGI) and the dielectric wall accelerator (DWA) to develop a compact proton accelerator for radiotherapy and radiosurgery that will be only a fraction of the footprint of current systems, which could be located in a single treatment room with significantly less infrastructure investment [1]. In addition, this architecture can provide real-time energy modulation to match the proton beam's Bragg peak to target tumours at different depths. Existing systems achieve this using a scattering mask, which results in production of neutrons that can pose health concerns for patients and treatment providers. In addition, the DWA system will be capable of a range of spot size control unmatched by existing PBT systems to enable treatment of different sizes and shape tumours.

*Portions of this work were performed by LLNL under Contract DEAC52-07NA27344, funded by CRADA \# TC02109.0 with CPAC
As a key milestone to full commercial deployment of this system, CPAC has successfully built a prototype DWA system to demonstrate operation of the subsystems and to retire engineering integration risks related particularly to the synchronization of the Radio Frequency Quadrupole (RFQ) to the DWA, operation of the Blumleins and solid state optical switches at high charge voltage of $>25 \mathrm{kV}$, and effectiveness of the HGI in the presence of a proton beam. The compact DWA prototype system starts with a proton beam generated in a duoplasmatron ion source and extracted at $35 \mathrm{keV}$. The protons are transported into the RFQ by two Einzel lenses that maintain the low emittance and focus the beam through the accelerator gating "kicker." The kicker fields steer the beam out of the acceptance of the RFQ, and then one or more RFQ buckets are filled by a fast deflecting pulse that nulls these fields. This kicker pulse, the 425 $\mathrm{MHz}$ of the RFQ and the laser pulse to the DWA switches are all timed with an innovative ultra-low jitter timing and control subsystem. The RFQ accelerates and bunches the input beam to output energy of $2 \mathrm{MeV}$ which the DWA accepts and accelerates to the final system energy. To enable operation of the DWA, other subsystems include a high power pulsed laser, a fiber optic distribution system, an electrical charging system, and beam diagnostics. Fig. 1 shows a block diagram of the complete system.

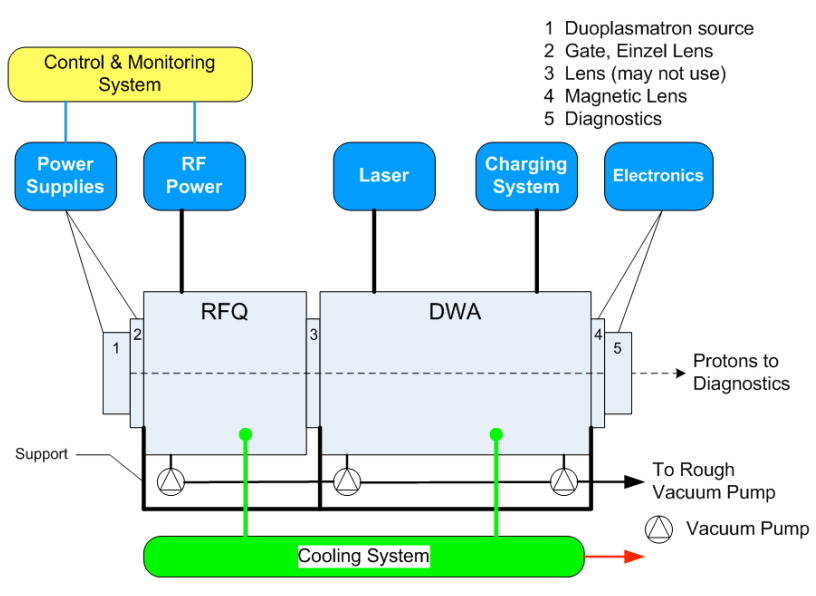

Figure 1: Prototype DWA system black diagram 


\section{SOURCE, LEBT, AND PULSED KICKER}

The proton ion source is a commercial duoplasmatron from AccSys Technology, Inc., also the manufacturer of the RFQ linac. The low-energy beam transport (LEBT) originally supplied by AccSys used a single Einzel lens between the source and RFQ that was not suitable to match the beam to the pulse selection deflector ("kicker"). This LEBT was replaced by a double Einzel lens design developed specifically for the DWA system [2]. Trajectories for a $35 \mathrm{~mA}$ proton beam in the final LEBT are shown in Fig. 2. The ion source gate valve cover on the left and the RFQ end plate on the right are used as the ground electrodes of the Einzel lens assembly. The kicker is built into a redesigned thicker RFQ end plate. The RFQ vanes are not shown on the right.

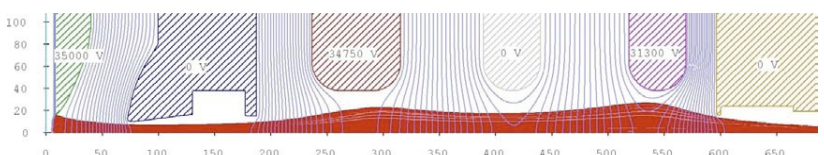

Figure 2: LEBT beam optics for DWA injector RFQ

As described above, the kicker changes the angle of the input protons so that they are either accelerated in the RFQ (no angle) or not accepted (outside of acceptance phase space). Calculated beam transmission vs. deflection angle at the RFQ entrance show that a deflection angle of only $100 \mathrm{mrad}$ stops the beam from being accelerated. Fig. 3 shows a schematic representation of the kicker and the actual RFQ end plate with the kicker assembly.

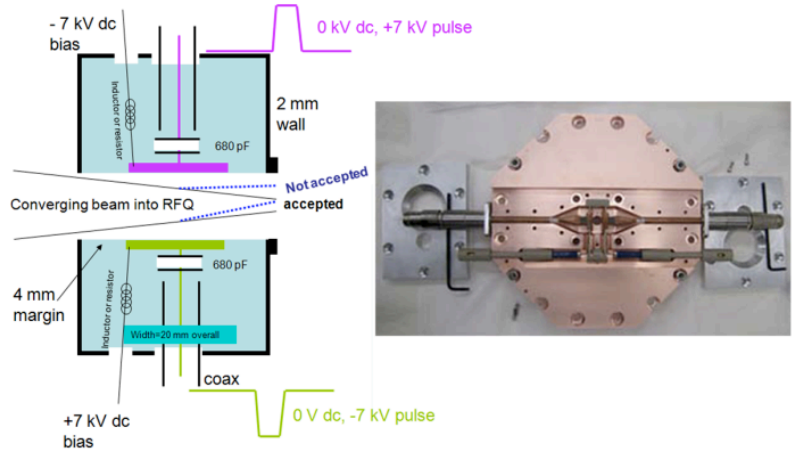

Figure 3: Kicker schematic \& actual assembly

\section{RFQ INJECTOR DESIGN}

The design parameters for the DWA injector RFQ linac are listed in Table 1 [3]. The RFQ structure is $1.2 \mathrm{~m}$ long and the current limit is more than twice the output current required for injection into the DWA, giving ample margin for its operation.

TABLE 1: DWA Injector RFQ Linac Parameters

\begin{tabular}{ll}
\hline \multicolumn{1}{c}{ Parameter } & \multicolumn{1}{c}{ Value } \\
\hline Operating frequency & $425 \mathrm{MHz}$ \\
Injection energy & $0.035 \mathrm{MeV}$ \\
Final beam energy & $2.0 \mathrm{MeV}$ \\
Design input current & $50 \mathrm{~mA}$
\end{tabular}

\section{Current limit}

Transmission at $50 \mathrm{~mA}(\%)$

Input transverse emittance (norm)

Nominal vane voltage

Bore radius

Maximum vane modulation

Structure length

Peak RF field surface gradient

Pulsed structure power

Pulsed beam power

Total input RF power

\section{SYSTEM TIMING}

In the prototype system, synchronization must be achieved across all seven major subsystems: (1) proton ion source, (2) kicker, (3) RFQ linac, (4) DWA, (5) Blumlein charging, (6) laser to trigger the switches and (7) the beam diagnostics. A diagram of the timing system is shown in Fig. 4.

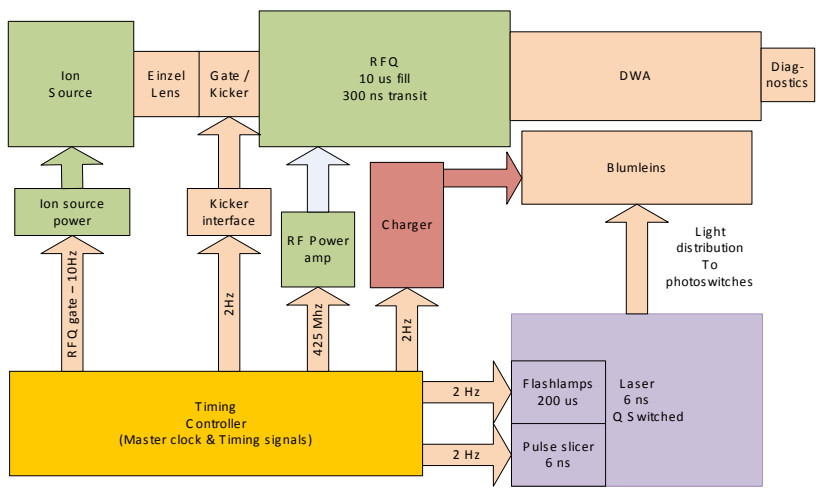

Figure 4: Timing block diagram

\section{HIGH-GRADIENT INSULATOR}

To sustain the high voltage generated by the Blumleins for accelerating the protons, high-gradient insulators (HGI) were developed as the acceleration tube. Surface flashover of insulators in vacuum is generally the limiting factor in the design of high voltage vacuum devices. The most widely-accepted theory of surface flashover holds that - an avalanche of secondary electrons occurs along the insulator surface, desorbing gas through which the breakdown occurs [4-7]. The HGI overcomes the flashover by inhibiting the breakdown process using closely-spaced, floating conductors, encapsulated in a dielectric. To validate the performance of the HGI, a special test setup with a $3 \mathrm{MV}, 1 \mathrm{~ns}$ Optoel pulser was employed. Fig. 5 shows a typical output waveform from this pulser used for these measurements.

Breakdown (i.e. arcing) was detected by monitoring light flashes inside the HGI and momentary pressure rises in the vacuum. Various samples were tested: $33 \mathrm{~mm}$ length HGI with varying conductor-to-dielectric thickness ratios and a $100 \mathrm{~mm}$ length HGI of a single conductor-todielectric thickness ratio, along with a baseline $33 \mathrm{~mm}$ long solid polyethylene piece. The maximum field on the best sample was $>80 \mathrm{MV} / \mathrm{m}$. 


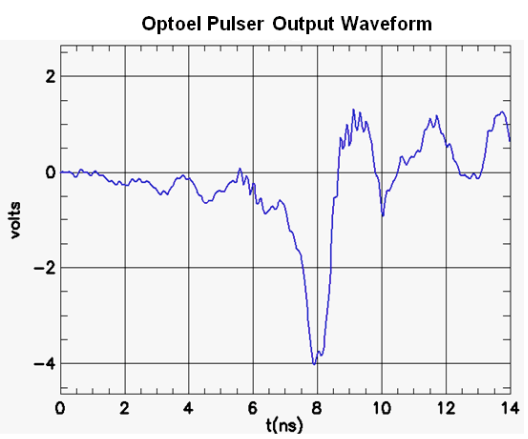

Figure 5: Pulser output waveform

\section{PROTOTYPE DWA RESULTS}

The DWA section of the engineering prototype is shown in Fig. 6. Total length of the High Gradient Insulator was $10 \mathrm{~cm}$ but only the center $3 \mathrm{~cm}$ were energized with two stacks of 15 blumleins each, positioned at diametrically opposite sides of the HGI. The Blumleins were approximately $60 \mathrm{~cm}$ long, $2 \mathrm{~cm}$ wide and $2 \mathrm{~mm}$ thick. Not shown are the RFQ, laser and charging systems.

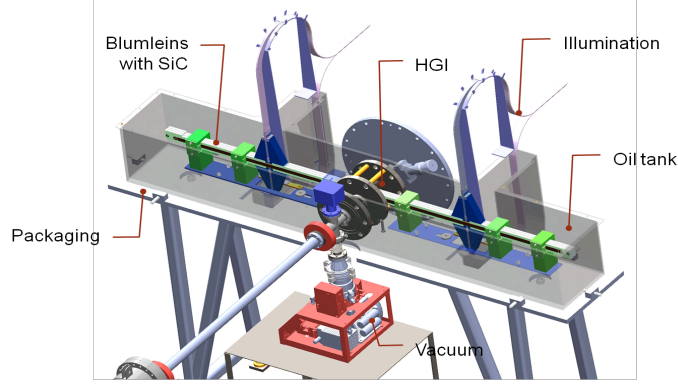

Figure 6: Prototype dielectric-wall-accelerator (DWA)

A time-resolved energy analyzer was constructed with $\mathrm{NdFeB}$ permanent magnets to deflect the protons along the horizontal axis and deflection plates with ramped voltage to separate the individual pulses out in time along the vertical axis. Images from this spectrometer are shown on the left of Fig. 7. The plot on the right is the energy gain of the middle pulse as the laser switch time of the DWA was varied during preliminary operation of the prototype, for several different charge voltages.

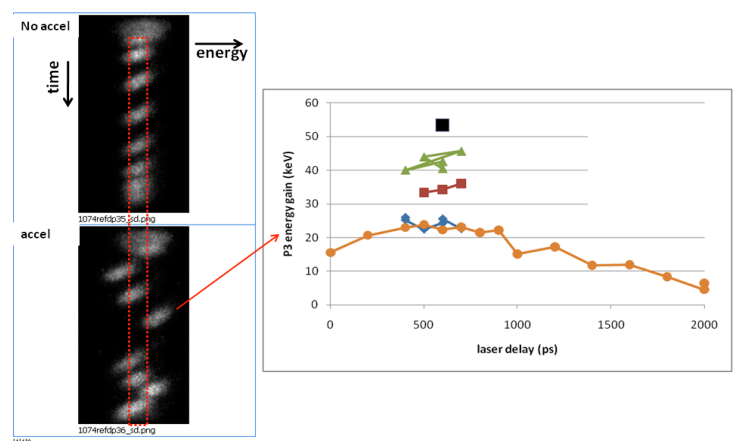

Figure 7: Time-resolved Thompson Parabola Spectrometer images and associated energy gain of proton pulse for different charge voltages
Acceleration was also measured by a time-of-flight technique. A fast ion collector was located $1 \mathrm{~m}$ from the prototype. The RFQ oscillator signal is used to derive a reference time for each proton bunch for comparison with the proton arrival time, and the energy is determined from change in flight time relative to unaccelerated bunches.

TOF data are shown in Fig. 8 for various charge voltages. The charge voltages are each represented by up to 25 shots filling in the acceleration waveform.

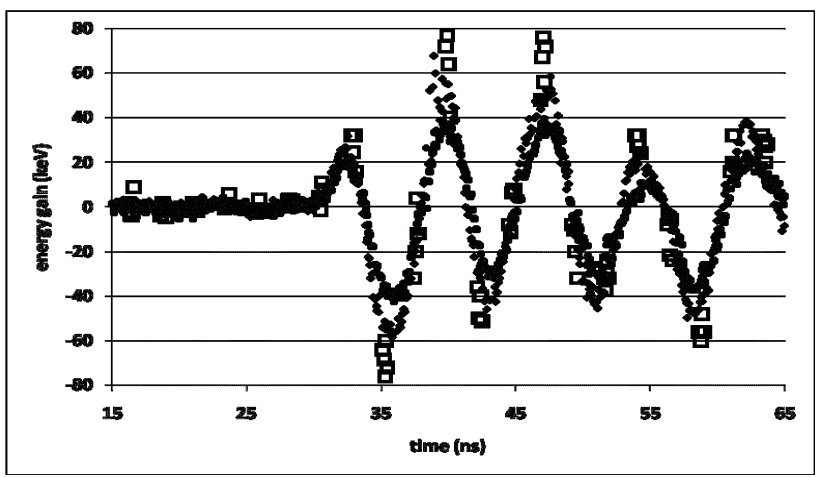

Figure 8: Prototype energy gain measured from ion collector time-of-flight for various charge voltages plotted relative to the time of laser switching.

\section{FUTURE MILESTONES}

Development of the DWA components further to achieve higher charge voltages and energy gain per charge volt is underway. New illumination and high voltage systems are also being developed to simplify the construction, decrease cost and improve the overall reliability of the system. CPAC plans to complete the construction of a higher capability prototype by the middle of 2012. A $150 \mathrm{MeV}$ fixed beam accelerator suitable for integration into a Proton Beam Therapy system is planned for completion by late 2013 .

\section{REFERENCES}

1. G. J. Caporaso et.al, High Gradient Induction Accelerator, Proc. PAC07, IEEE Catalog No: 07CH37866, 2007, pp 857-861.

2. R. Becker, R. W. Hamm and H. Pearce-Percy, Electrostatic Matching of a High Current Proton Beam to a RFQ, this proceedings.

3. R. W. Hamm et al., A Single Pulse Subnanosecond proton RFQ, Proc. AccApp 11, April 2011, Knoxville, TN (to be published).

4. H. Craig Miller, IEEE Trans. Elect. Insul. 24(5), 765-785 (1989).

5. H. Boersch et al., Z. Agnew. Physik 15, 518-525 (1963).

6. E. W. Gray, J. Appl. Phys. 58, 132 (1985).

7. J. R. Harris et al., Multilayer High-Gradient Insulators, IEEE Trans. on Dielectrics and Electr. Insulation, vol. 14, no. 4, pp. 796-802, 2007. 